\title{
ASSESSMENT OF CLINICAL EFFICACY OF COOLING GEL PATCH
}

\author{
Muhammad Hussain, Muhammad Asim, Muhammad Atif, Naveed Anjum \\ 78 Medical Battalion, Okara Cantt Pakistan
}

\begin{abstract}
Objective: To determine the efficacy of cooling gel patch in various clinical indications and comparison of cooling gel patch with water spray and cold sponging in fever and heat exhaustion.

Study Design: Comparative cross sectional study.

Place and Duration of Study: Garrison Medical Centre Okara Cantt, from Sep to Dec 2018.

Methodology: A total of 48 male patients, age ranges from 20-40 years were assessed with different clinical indications of cooling gel patch. Patients with fever, heat exhaustion, headache, muscle cramps and toothache were included in this study and patients with acute illness other than fever were excluded. A control group of 20 individuals was also analyzed against fever and heat exhaustion in which water spray and cold sponging was used. Frequency and percentages of each indication were calculated and chi square test was applied.

Results: Total of 48 individuals living in plain terrain with various clinical indications of cooling gel patch were assessed. Cooling Gel Patch was tested on 16 sportsmen with heat exhaustion out of which 2 (12.5\%) individual had minimal effect whereas control group of 10 showed good response in $8(80 \%)$ sportsmen with water spray and cold sponging with $p$-value .000578 . Six patients with headache and 4 individuals with toothache reported no reduction in symptoms. Two out of 6 patients with muscle cramps reported mild relief in symptoms. Sixteen patients reported with high grade fever and out of these, $12(75 \%)$ individuals showed no reduction in temperature after 4 hours of application. In $4(25 \%)$ cases fall of $1^{\circ} \mathrm{F}$ was observed after 2 hrs but no further decrease noted from $4-8$ hrs whereas control group of 10 individuals showed very good response with water spray and sponging with $p$-value <.0001. Fourteen $(29 \%)$ out of 48 reported individuals felt cooling effect for 30 minutes or less. Moreover 4 individuals reported bad/unpleasant odour. Twenty six (54\%) out of 48 individuals reported varying degrees of itching/irritation after application of cooling gel patch on the skin.

Conclusion: Cooling gel patch is not a preventive/curative modality against fever, headache, toothache, muscle cramps and heat stroke. Water spray and cold sponging is proved to be more affective in patients for temperature lowering and heat exhaustion when compared with cooling gel patch.
\end{abstract}

Keywords: Cooling gel patch, Fever, Heat exhaustion, Muscle cramps, Pain management, Water spray.

This is an Open Access article distributed under the terms of the Creative Commons Attribution License (http://creativecommons.org/licenses/by/4.0), which
permits unrestricted use, distribution, and reproduction in any medium, provided the original work is properly cited.

\section{INTRODUCTION}

Exercise increases the core body temperature especially in warm and humid conditions which increase temperature gradient between the skin and environment and the capacity for heat loss is reduced. These components along with an increase in metabolic heat production, decrease work capacity, exercise performance and may develop heat related illnesses ${ }^{1}$. There are different cooling strategies which can increase heat storage capacity, attenuate the exercise induced increase in body temperature and rapid recovery after intense exercise ${ }^{1}$. Exercise induced stress leads to

Correspondence: Dr Muhammad Hussain, 78 Medical Battalion, Okara Cantt, Pakistan

Received: 17 May 2019; revised received: 28 Jul 2020; accepted: 30 Jul 2020 hyperthermia, inflammation, muscle damage and nervous system fatigue that results in reduced performance potential ${ }^{2}$. Thermoregulatory receptors located within the skin, convey information on this accumulation of thermal energy to higher brain which produce inhibitory signals that lower the work capacity by decreasing metabolic heat production to protect body from heat injury ${ }^{1,2}$. These inhibitory signals may help to maintain exercise performance in the heat. These inhibitory signals may be inhibited by cooling the skin and deep body temperature pre, per and post during exercise by cooling vest, ice slurry ingestion, cold water immersion, cryotherapy or perhaps by applying menthol or different combination of these on the skin ${ }^{3,4}$. 
Menthol is an organic compound derived from the genus Mentha (mint), which is widely available in natural and synthetic formations. Menthol activates cold receptors in the skin to elicit cooling effects once applied locally on the skin especially on head and neck region which have greater density of cold sensitive afferent thermal receptors 5,6 . These receptors are not activated in the body, unless cooled below $27^{\circ} \mathrm{C}$. Menthol is also used as vasoactive agent that produces cutaneous vasodilation ${ }^{6}$. When menthol applied to the skin of heat stressed individuals, may provide a cooling effect to neuronal input to higher brain structures in addition to the neuronal signals arising from warm thermo receptors located within the body ${ }^{7}$.

Menthol also acts as weak sodium channel blocker. This mechanism dependent on voltagegated neuron channel which communicate a weak and localized anesthetic effect ${ }^{6}$. But menthol may also induce a heat storage (cold defense) response. Menthol also have some common side effects such as itching, dry skin, skin irritation, burn, difficulty in breathing, edema, hives, hypersensitivity and anaphylaxis ${ }^{8}$. This study will help to understand the effectiveness of different cooling techniques as no such study is conducted in Pakistan.

\section{METHODOLOGY}

A comparative cross sectional study was conducted at Garrison Medical Centre Okara cantonment from Sep 2018 to Dec 2018 with approval of Institutional Review Board (IRB) certificate number $01 / 2018$. A total number of 48 male patients with non-probability consecutive sampling technique, age ranges from 20-40 years with clinical indications of fever, heat exhaustion, headache, muscle cramps and toothache were included in this study and patients with acute illness other than fever were excluded. Sample size was calculated by WHO sample size calculator taking confidence level of $80 \%$, absolute precision of 0.10 , and population mean of 2.4 (reduction of temperature with cooling gel), and population SD of 0.51 . The minimum sample size required was 43 patients 9 .

A control group of 20 individuals was also analyzed and compared with fever and heat exhaustion in which water spray and cold sponging was used. The Cooling gel patch composition includes menthol $0.2 \%$ (active agent), Glycerin and Sodium Polyacrylate (gel forming substances), Aluminum Glycinate and Methyl Methacrylate (sticking agents), Tartaric Acid (disperse menthol evenly), Pigment- Brilliant Blue (coloring agent) and Water 76\% (base). Cooling gel patch measured $5 \times 12 \mathrm{cms}$, applied on different parts of body such as on forehead for fever and headache, on thigh for muscle cramps, on back of neck for heat exhaustion, as recommended in manufacturer's instructions. Frequency and percentages of different clinical indications were calculated and chi square test was applied. Data was recorded in SPSS version 23.

\section{RESULTS}

Total 48 individuals with various clinical indications for cooling gel patch were evaluated. Cooling Gel Patch was tested on 16 sportsmen with heat exhaustion, out of which 2 individual $(12.5 \%)$ showed weak effect whereas control group of 10 sportsmen with heat exhaustion showed good response to water spray and cold sponging in $8(80 \%)$ of individuals (table-I) with $p$-value

Table-I: Comparison of experimental \& control group for heat exhaustion.

\begin{tabular}{l|c|c|c}
\hline \multicolumn{4}{|c}{ Heat Exhaustion } \\
\cline { 1 - 3 } & Benefit & No benefit & $p$-value \\
\hline $\begin{array}{l}\text { Cooling gel } \\
\text { patch }\end{array}$ & $2(12.5 \%)$ & $14(87.5 \%)$ & \multirow{2}{*}{0.000578} \\
$\begin{array}{l}\text { Water \& } \\
\text { Sponging }\end{array}$ & $8(80 \%)$ & $2(20 \%)$ & \\
\hline
\end{tabular}

Table-II: Comparison of test \& control group in fever.

\begin{tabular}{l|c|c|c}
\hline \multicolumn{4}{c}{ Fever } \\
\hline & Benefit & No Benefit & $p$-value \\
\hline $\begin{array}{l}\text { Cooling gel } \\
\text { patch }\end{array}$ & $4(25 \%)$ & $12(75 \%)$ & \\
\cline { 1 - 2 } $\begin{array}{l}\text { Water spray } \\
\text { \& sponging }\end{array}$ & $10(100 \%)$ & - & 0.00019 \\
\hline
\end{tabular}

0.000578. Six patients with headache and 4 individuals with toothache were applied with cooling 
gel patch and no reduction in pain was reported. Six sportsmen with muscle cramps were treated with cooling gel patch but only two mentioned mild relief in symptoms (table-III). Sixteen patients reported with high grade fever and all these patients were applied with cooling gel patch on their forehead for $8 \mathrm{hrs}$. Out of these 16 patients, $12(75 \%)$ individuals showed no reduction in temperature and only $4(25 \%)$ patients with fever showed fall of $1^{\circ} \mathrm{F}$ of temperature after $2 \mathrm{hrs}$ but no further decrease was noted from 4 to $8 \mathrm{hrs}$

Table-III: Summary of effects of cooling gel patch.

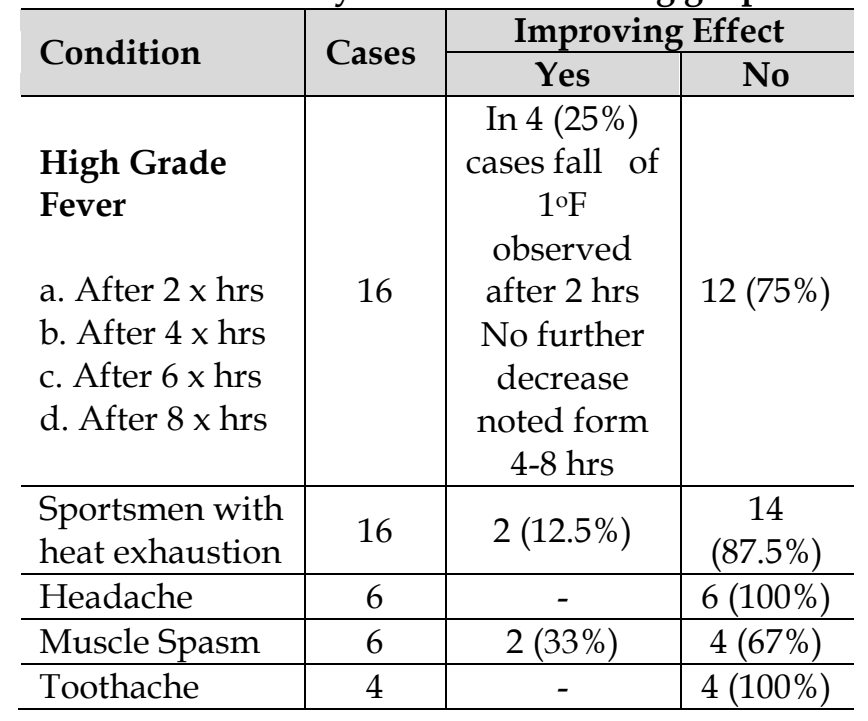

whereas control group of 10 individuals with fever showed very effective response to water spray and sponging (table-II) with $p$-value .00019 . Fourteen (29\%) individuals out of 48 reported that cooling effect of cooling gel patch usually last for 30 minutes or less. Out of 48 analyzed populations, 4 individuals reported about unpleasant odour. Twenty six (54\%) individuals reported about varying degrees of itching/irritation after application of cooling gel patch on the skin.

\section{DISCUSSION}

Multiple studies carried out in the past to determine the effectiveness of cooling techniques such as menthol and its various compositions like water spray, cold sponging, cooling vest, ice slurry ingestion, cold water immersion, cryotherapy in reducing heat related stresses in individuals exposed to hot and humid environment. A study conducted at Beijing at International association of athletic federation's world championships of 2015 in which $47 \%$ of athletes used cold water immersion and $24 \%$ used ice slurry ingestion cooling techniques as a post exercise recovery strategy ${ }^{6}$. Result suggests and emphasize that more athletes could benefit from these cooling techniques $^{6}$. Our study also suggested water spray and cold sponging as effective way of post exercise recovery.

Another study conducted at Beijing Olympics in 2008 by applying a commercially available cooling solution spray composed of $0.2 \%$ menthol 7 . The objective of the study was to determine menthol efficacy in reducing heat stress among athletes and sports staff working in hot $\left(30^{\circ} \mathrm{C}\right)$ and humid climate of Beijing on the request of UK Sports committee. The results concluded that menthol neither improve, nor reduce thermal comfort, but resulted in heat storage response. In the control group water spray was used to cool the skin without inducing any heat storage response. Water spraying was recommended by UK Sports committee over the menthol spray ${ }^{7}$. Our study also showed that water spray was more effective as compared to menthol containing cooling gel patch.

A study conducted by Barwood et al, in which 8 healthy male participants volunteered in cycling time trial at $33.5^{\circ} \mathrm{C}, 33 \%$ relative humidity in which water spray and menthol spray was used resulted in no difference in performance but menthol sprayed individuals felt cooler and more comfortable9. This study concluded that menthol use in exercise improves heat perception but did not alter performance and did not increase risk of heat illness.

Studies conducted by Topp and Johar et al concluded that Menthol also activates the central analgesic pathways. Recent understanding of TRPM $^{8}$ channels have provided a molecular basis for understanding the molecular action of menthol and its ability to produce both a cooling sensation and reduction in pain ${ }^{10,11}$. The more under- 
standing of pharmacologic mechanism of menthol may lead to expand its role for replacements for opioid analgesics, particularly those that can be applied topically ${ }^{12,13}$. In this study at $0.2 \%$ menthol concentration was used and at this low concentration, no pain relief was observed.

A study conducted by Watson et al, observed that the cooling effects usually effective not more than 15 minutes and cooling sensation also varies with site of application and dose of methanol used in preparation ${ }^{14}$. Our study concluded that about $29 \%$ of participants had cooling sensation for about 30 minutes and $71 \%$ had mild cooling sensation for only few minutes.

A study conducted by Kounalakis et al in 2010, in which 66 adults suffering from musculoskeletal pain, a topical product containing methanol lower the pain ${ }^{15}$. This study showed no pain relief when applied in individuals with headache and toothache but our study data was small and further study with large group is needed but mild muscular spasm was relieved in $23 \%$ of individuals.

A study conducted by O'Hara et al on soldiers of United Kingdom in hot and humid environment of UK concluded that acclimatization should be done before going to hot and humid conditions, light weight clothes should be wearied and hydration level should be maintained during physical activity, are simple techniques that can attenuate heat stress ${ }^{16}$.

A randomized double blinded controlled study was conducted by Airaksinen et al, in which seventy-four patients were assessed the efficacy of cold gel with placebo gel in sports related soft tissue injuries which showed better satisfaction with cold gel as compared to placebo gel17.

Two different studies conducted by Ried and Peier et al concluded that the use of menthol in different preparations associated with itching, respiratory and cutaneous adverse reactions, anaphylaxis from different mechanisms including type-1 (IgE-mediated hypersensitivity), type-IV (delayed-type hypersensitivity) and non-immu- nologic histamine release ${ }^{18,19}$. In our study, $55 \%$ of the individuals showed mild to moderate itching with cooling gel patch containing menthol which may increase with repeated use and can lead to anaphylaxis and death.

\section{RECOMMENDATION}

Standard preventive measures for fever and heat exhaustion may be adopted in place of using cooling gel patch.

Pre cooling techniques such as water spray, cold water immersion, cooling vest, cold water ingestion and ice slurry ingestion may be used as preventive measures.

Moderate effect of cooling gel patch on muscle spasm may need further large data analysis.

Itching and odour produced by cooling gel patch may irritate the patient and may need avoidance in some patients because of fear of allergy and anaphylaxis.

Further scientific evidence based testing or trial may be conducted at appropriate institute.

\section{CONCLUSION}

The use of cooling gel patch in different clinical indication was assessed. Cooling gel patch is not a preventive / curative modality against fever, headache, toothache, muscle cramps and heat stroke. No positive effect noticed in treating headache and toothache whereas very moderate effect was experienced in sprain and muscle spasm cases with cooling gel patch. Current methods of temp control and heat exhaustion such as water spray/sponging were more effective as compared to cooling gel patch. Cooling gel patch was not effective in temperature lowering, pain management and heat exhaustion.

\section{CONFLICT OF INTEREST}

This study has no conflict of interest to be declared by any author.

\section{REFERENCES}

1. Bongers CC, Hopman MT, Eijsvogels TM. Cooling interventions for athletes: an overview of effectiveness, physiological mechanisms, and practical considerations. Temperature 2017; 4(1): 60-78. 
2. Valente A, Carrillo AE, Tzatzarakis MN, Vakonaki E, Tsatsakis AM, Kenny GP, et al. The absorption and metabolism of a single L-menthol oral versus skin administration: Effects on thermogenesis and metabolic rate. Food Chem Toxicol 2015; 86(1): 262-73.

3. Hunter AM, Grigson C, Wade A. Influence of topically applied menthol cooling gel on soft tissue thermodynamics and arterial and cutaneous blood flow at rest. Int J Sports Phys Therap 2018; 13(3): 483-88.

4. Gillis DJ, House JR, Tipton MJ. The influence of menthol on thermoregulation and perception during exercise in warm, humid conditions. Eur J Appl Physiol 2010; 110(3): 609-18.

5. Liu B, Fan L, Balakrishna S, Sui A, Morris JB, Jordt SE. TRPM8 is the principal mediator of menthol-induced analgesia of acute and inflammatory pain. Pain 2013; 154(10): 2169-77.

6. Premkumar LS, Abooj M. TRP channels and analgesia. Life Sci 2013; 92(8-9): 415-24.

7. Periard JD, Racinais S, Timpka T, Dahlström O, Spreco A, Jacobsson J, et al. Strategies and factors associated with preparing for competing in the heat: a cohort study at the 2015 IAAF world Athletics Championships. Br J Sports Med 2017; 51(4): 264-70.

8. Haeseler G, Maue D, Grosskreutz J. Voltage-dependent block of neuronal and skeletal muscle sodium channels by thymol and menthol. Eur J Anaesthesiol 2002; 19(8): 571-79.

9. Barwood MJ, Corbett J, Thomas K, Twentyman P. Relieving thermal discomfort: Effects of sprayed L-menthol on perception, performance, and time trial cycling in the heat. Scand J Med Sci Sports 2015; 25(Sippl-1): 211-18.

10. Topp R, Ledford ER, Jacks DE. Topical menthol, ice, peripheral blood flow, and perceived discomfort. J Athl Train 2013; 48(2): 220-25.
11. Johar P, Grover V, Topp R, Behm DG. A comparison of topical menthol to ice on pain, evoked tetanic and voluntary force during delayed onset muscle soreness. Int J Sports Phys Ther 2012; 7(3): 314-22.

12. Gillis DJ, Barwood MJ, Tipton MJ. The effect of 1-menthol on thermoregulation sensation and exercise performance in Beijinglike conditions. The Department of Sports and Exercise Science, the University of Portsmouth and UK Sport. August 2008.

13. Schlader ZJ, Simmons SE, Stannard SR, Mündel T. Skin temperature as a thermal controller of exercise intensity. Eur J Appl Physiol 2011; 111(8): 1631-39.

14. Lasanen R, Julkunen P, Airaksinen O, Toyras J. Menthol concentration in topical cold gel does not have significant effect on skin cooling. Skin Res Technol 2016; 22(1): 40-45.

15. Kounalakis SN, Botonis PG, Koskolou MD, Geladas ND. The effect of menthol application to the skin on sweating rate response during exercise in swimmers and controls. Eur J Appl Physiol 2010; 109(2): 183-89.

16. O'Hara R, Eveland E, Fortuna S, Reilly P, Pohlman R. Current and future cooling technologies used in preventing heat illness and improving work capacity for battlefield soldiers: review of the literature. Mil Med 2008; 173(7): 653-57.

17. Airaksinen OV, Kyrklund N, Latvala K, Kouri JP, Grönblad M, Kolari P. Efficacy of cold gel for soft tissue injuries: a prospective randomized double-blinded trial. Am J Sports Med 2003; 31(5): 680-84.

18. Reid G. Thermo TRP channels and cold sensing: what are they really up to?. Pflügers Arch 2005; 451(1): 250-63.

19. Peier AM, Moqrich A, Hergarden AC, Reeve AJ, Andersson DA, Story GM, et al. A TRP channel that senses cold stimuli and menthol. Cell 2002; 108(5): 705-15. 